\title{
Effect of low radiation dose on the expression and location of aquaporins in rat submandibular gland
}

\author{
M.V.T. Araujo ${ }^{a}$, M.A. Spadella ${ }^{a}$, A.B. Chies $^{\mathrm{a}}$, G.V. Arruda ${ }^{\mathrm{a}}$, T.de M. Santos ${ }^{\mathrm{b}}$, M.M. Cavariani ${ }^{\mathrm{b}}$, \\ R.F. Domeniconi ${ }^{\mathrm{b}, *}$ \\ ${ }^{\text {a }}$ Faculty of Medicine of Marília (FAMEMA), Marília, SP, Brazil \\ ${ }^{\mathrm{b}}$ Department of Anatomy, Institute of Biosciences, Univ Estadual Paulista, Botucatu, SP, Brazil
}

A R T I C L E I N F O

\section{Keywords:}

Salivary glands

Irradiation

Water channels

\begin{abstract}
A B S T R A C T
Head and neck cancers are common in several regions of the world and the treatment usually includes radiotherapy. This treatment can generate adverse effects to the salivary flow, with a relationship between the dose and the damage caused. Salivary gland cells are highly permeable to water and therefore, they express aquaporins (AQPs). This study analyzed changes in the expression and location of these proteins and identified morphological changes induced by low radiation in rat submandibular gland. Female rats were divided into control and irradiated groups. Immunohistochemistry analysis allowed confirming the presence of AQP1 in the blood vessel endothelium. Intense and steady labelling granules were also observed in the cytoplasm of submandibular gland ductal cells. In addition, there was AQP5 positive labelling in ductal cells delimiting the lumen of intercalated duct, in the cytoplasm and membrane of acinar cells. Finally, the decrease of AQP labelling in irradiated animal glands validated their radiosensitivity. Thus, the decrease in AQP1 protein levels in the endothelium and AQP5 in gland ductal cells of irradiated animals may have hindered the removal of water from the lumen of ductal cells, inducing a delay in water absorption and triggering a slight lumen increase.
\end{abstract}

\section{Introduction}

Salivary glands might undergo changes that lead to hypofunction during the aging process. Besides aging, diabetes mellitus; use of antidepressants, antihypertensive and diuretics; as well as radiation therapy for tumorous diseases (Rosa et al., 2008; Jham and Freire, 2006; Lucena et al., 2010; Vieira et al., 2012; Deasy et al., 2010; Liu et al., 2012); or even menopause (Minicucci et al., 2013) and autoimmune diseases such as Sjogren's Syndrome (Jensen and Vissink, 2014), also alter salivary glands function.

Changes in salivary glands and the impact on volume and quality of saliva may have harmful deleterious consequences for the oral cavity in dentate individuals, in which the lack of saliva affects, in particular, the ability of oral tissues to defend itself against external aggressions (Saleh et al., 2015). In partially and fully edentulous individuals, the saliva is being related to defence capabilities and also plays a fundamental role in stabilizing removable prosthetic devices, which is a factor of high importance for health, comfort and ability to chew in these individuals (Nikolopoulou et al., 2013).

Head and neck cancer accounts for $5 \%$ of all malignancies and the treatment protocol for this kind of tumours may include surgery and/or radiotherapy of the oral cavity, maxilla, mandible and salivary glands, which can generate numerous adverse effects to the volume and quality of salivary flow (Jham and Freire, 2006; Vieira et al., 2012; Deasy et al., 2010; Liu et al., 2012).

Deasy et al. (2010) report that reduction in salivary function may start around 1 week after initiation of irradiation therapy, gradually returning after 2 years in cases where radiation does not induce severe and irreversible damage to the glands. Wong (2014) reports an index above $90 \%$ of prevalence of some kind of injury to the oral cavity after radiotherapy treatment; xerostomia being the most commonly reported sequel. Lastly, Pinna et al. (2015) conclude that ionizing radiation-induced xerostomia may be considered a multifactorial disease dependent on the chosen type of cancer treatment, as well as the radiation dose applied to the tissues.

Aquaporins (AQPs) are water channels that facilitate and regulate water transport across cellular membranes (Verkman and Mitra, 2000). These proteins are expressed in plasma membrane of cellular types involved in fluid transport and they are present in the membrane of intracellular organelles, thus, regulating cell and organelle volumes (Nozaki et al., 2008). AQPs are involved in a great variety of physiological functions, such as secretory function and homeostasis of water

\footnotetext{
* Corresponding author at: Department of Anatomy, Biosciences Institute, UNESP - Univ Estadual Paulista, P.O. Box 510, Rubião Júnior, s/n, Botucatu, SP 18618-689, Brazil.

E-mail address: rdomeniconi@ibb.unesp.br (R.F. Domeniconi).
} 
and solutes, assisting the transepithelial fluid transport. They also participate in many pathological processes such as glaucoma, epilepsy, obesity and cancer (Verkman, 2005, 2009). Acinar epithelial cells of salivary glands show high permeability to the passage of water, and therefore, have AQPs (Delporte, 2013; Aure et al., 2014; Delporte and Steinfeld, 2006; Matsuzaki et al., 2012; Takahashi et al., 2015; Takakura et al., 2007; Susa et al., 2013).

AQP5 has been the most studied protein in salivary glands and some works have shown that this AQP plays fundamental role in the secretion of fluids in this kind of tissue (Li et al., 2006a, 2006b; Delporte, 2013; Aure et al., 2014). Studies with rodents have identified AQP5 in the parotid, sublingual, and especially, submandibular glands. AQP5 is localized in the apical membrane of serous acinar cells in the submandibular gland where it plays a role in primary saliva production ( $\mathrm{Li}$ et al., 2006a, 2006b). In the cells of submandibular gland ducts, the presence of this AQP is controversial and still requires further investigation (Delporte and Steinfeld, 2006).

The radiation used in the treatment of head and neck cancer causes damage to the acinar cells of salivary glands (Johnson et al., 1993). Moreover, a decrease in AQP5 expression in salivary glands of irradiated mice was observed. This decrease might participate in the mechanisms that lead to salivary flow loss (Delporte, 2013; Delporte and Steinfeld, 2006).

AQP1 is also seen in blood vessels of submandibular glands during natal and post-natal rat development. The immunolocalization of AQP1 in human salivary glands has shown that, besides capillaries, this AQP is also associated to myoepithelial cells. In patients with Sjögren's syndrome, an auto-immune disease with unclear ethiopathology, which presents the hypofunction of lacrimal and salivary glands as symptom, a decreased expression of AQP1 is observed in myoepithelial cells, which suggests that this AQP might be involved with salivary gland malfunctions (Delporte and Steinfeld, 2006).

Despite existing literature, little is known about the role of AQPs in salivary glands, and generally, these studies report contradictory data about the expression and/or location of some AQP subtypes. Moreover, experimental studies are lacking in the background scientific literature that could describe the impact of radiation treatments on the salivary glands water channels and studies diverge in relation to intensity and fractionation of the dose. There seems to be a consensus that there is a relationship between the dose and the damage caused. Thus, to add new information about rat submandibular gland, our study proposed to investigate the pattern of AQP localization and identify possible morphological changes induced by low radiation dose in this gland.

Therefore, we have proposed this research to describe the location of AQPs 1 and 5, and to evaluate the effect of low radiation on these AQPs in rat submandibular gland, correlating it with possible general morphology changes and morphometry of these glands.

\section{Material and methods}

This study used 12 female Wistar rats, 10 weeks old, obtained from the Animal Facility of the Marilia Medical School - FAMEMA (Biotério Central da Faculdade de Medicina de Marília). The rats were fed with common solid diet and ad libitum water, and had adequate lighting and temperature conditions (12-hour light-dark cycle; $23-25^{\circ} \mathrm{C}$ ).

\subsection{Experimental groups}

The animals were randomly divided into two experimental groups (6 animals each), control and irradiated groups. Both the groups, subjected to radiation and the control, were anesthetized with ketaminxylazine $(\mathrm{v} / \mathrm{v}) 70 \mathrm{mg} / \mathrm{kg}-7 \mathrm{mg} / \mathrm{kg}$ and both groups were placed in treatment position within a box with abducted limbs and hyperextended neck.

\subsection{Radiotherapy protocol}

To undergo the radiation procedures, after anaesthesia induction, the animals were fixed to a platform. Anaesthesia was administered to prevent movement during the radiation beam emission period. The neck region was irradiated after placement of a lead cone to shield the path of radiation, then allowing only the submandibular gland irradiation. The rats were irradiated with a 7.5-Gy single dose of ionizing radiation emitted from a linear accelerator, VARIAN 6EX brand, positioned at a $20 \mathrm{~cm}$ distance from the skin surface. Tomography of the cervical region of the animal was carried out to ensure that the prescribed dose has been delivered to the target organ, avoiding the exposure of surrounding structures (oral cavity, esophagus and trachea), as much as possible. The rats in the control groups were not irradiated.

Fourteen days after neck irradiation, the rats in the control and irradiated groups were euthanized for the collection of submandibular glands. To minimize pain and suffering during the experiments, all animals were exposed to $\mathrm{CO}_{2}$ chambers to decrease consciousness and thereafter, they were sacrificed. The whole experiment and the surgical procedures present in this study are in accordance with the recommendations of the Canadian Council on Animal Experimentation and were approved by the Ethics Committee on Animal Use (CEUA) FAMEMA, Protocol 414/15. The research was conducted according to ethical principles in animal research adopted by the National Council for Animal Experiments Control (CONCEA).

During the experimental protocol, a daily monitoring of animals was performed for quantification of food and water intake, as well as animals' body weight.

\subsection{Material processing}

The submandibular glands were dissected and weighed, and the right-side ones were immediately frozen in liquid nitrogen and stored in an $-80{ }^{\circ} \mathrm{C}$ freezer, while the left-side ones were fixed in $4 \%$ Sorensen in $0.1 \mathrm{M}$ phosphate buffer glutaraldehyde and $2 \%$ formaldehyde fixing solution, $\mathrm{pH} 7.3$, for at least $24 \mathrm{~h}$. After fixation, the glands were dehydrated in ascending concentration series of alcohol solutions $(70 \%$, $80 \%$ and $90 \%$ ) and kept in $95 \%$ alcohol for $4 \mathrm{~h}$. The samples for morphometric analysis were submitted to 1:1, 95\% alcohol and plastic resin infiltration for $4 \mathrm{~h}$; infiltration in infiltrating resin for $4 \mathrm{~h}$ or overnight, and lastly, inclusion in glycol methacrylate (Leica Historesin Embedding Kit). Five micrometer thick sections were obtained from Leica RM2245 microtome equipped with a glass blade and were stained using hematoxylin and eosine. The samples obtained for the immunohistochemistry study were fixed by $4 \%$ PBS paraformoldehyde immersion for $24 \mathrm{~h}$, dehydrated in ethanol and followed routine for inclusion in Paraplast (Paraplast Plus, St. Louis, MO, USA), and subsequently, sectioned in $4 \mu \mathrm{m}$ thick sections in a microtome and then collected in silanized slides to be stored until use.

\subsection{Morphometric analysis}

The obtained slides were analyzed using a microscope (Olympus Microscope BX41 model) coupled to a digital video camera (Olympus, SD 25 model, DP2-BSW-Olympus Software), and the images were submitted to analysis of the following parameters: tissue volume, duct diameter and lumen.

The slides intended for volume morphometric analysis were assessed considering the equivalent percentage of ducts, acini and stroma, obtained by points counting through planimetric counting method, which is based on placing a grid totalling 168 points on the captured image, using the Image-Pro Plus Software.

Two slides for each animal were analyzed, with 6 animals per experimental group, yielding 36 histological fields per animal, in a random manner, while avoiding areas with preparation artefacts. Data were tabulated, achieving a percentage related to ducts, acini and 
stroma per animal, according to the following formula: \% (acini/duct/ stroma) $=$ number of matching points $\times 100 / 168$.

For the diameter analysis, 36 histological fields were randomly captured per animal, with 6 animals per experimental group, where measurements of area; perimeter; maximum, medium and minimal diameter of duct and lumen were obtained by cellSens Dimension Olympus software.

The maximum duct and lumen diameter average values allowed the calculation of duct epithelial tissue height (EH) and epithelial height/ lumen ratio through the following formula: $(\mathrm{EH}=$ arithmetic average of maximum duct diameter - arithmetic average of maximum lumen diameter. EH/Lumen Ratio = EH/Average Lumen Diameter).

The average of the collected data was submitted to statistical analysis by using GraphPad Prism ${ }^{\circledR}$ and $t$-test was utilized.

\subsection{Immunohistochemistry}

For the immunolocalization of AQPs 1 and 5, sections were deparaffinized and submitted to antigenic activity recovering in sodium citrate buffer $\mathrm{pH}=6.0$ for $15 \mathrm{~min}$ in a microwave. After washing in distilled water, the sections were submitted to endogenous peroxidase blocking (hydrogen peroxide in 3\% methanol) for $15 \mathrm{~min}$ in the dark and to unspecific proteins blocking with skim milk (MOLICO $\left.{ }^{\circledR}\right)$ at $3 \%$ in PBS buffer for $1 \mathrm{~h}$. After these procedures, the sections were incubated with primary anti-aquaporin-1 antibodies (1:1000 concentration; Millipore ${ }^{\circledR}$ Temecula, USA, AB2219) and anti-aquaporin-5 (1:500 concentration; Millipore ${ }^{\circledR}$ Temecula, USA, AB15858). After overnight incubation in the refrigerator with the primary antibodies, the sections were washed in PBS buffer solution and then incubated with the antirabbit secondary antibodies (1:200 concentration HRP SIGMA ${ }^{\circledR}$, USA) for $2 \mathrm{~h}$ at room temperature. After the reaction, the slides were revealed with DAB chromogen (3,3'-diaminobenzidine tetrahydrochloride SIGMA $^{\oplus}$, USA) and counterstained with hematoxylin for $1 \mathrm{~min}$. The yielded slides were analyzed and photographed in a microscope Axiophot - 2, with a digital camera, AxioCam HR Zeiss Model, from the Department of Anatomy, Institute of Biosciences - UNESP - Botucatu. To confirm the specific reaction, the efficiency of implemented technique and reagents, negative and positive controls were used.

\subsection{Western blotting}

Fragments of frozen submandibular glands were homogenized at $4{ }^{\circ} \mathrm{C}$ in RIPA buffer (Pierce Biotechnology, Rockford, IL, USA) and protease inhibitors (Sigma Chemical Co) at a ratio of $30 \mathrm{mg}$ tissue/ $100 \mu \mathrm{l}$ of buffer extraction in Tureaux type homogenizer in 3 cycles of $5 \mathrm{~s}$. The homogenate was centrifuged at $15,000 \mathrm{rpm}$ for $20 \mathrm{~min}$ at $4{ }^{\circ} \mathrm{C}$ and the supernatant was collected. The quantification of proteins was performed in 96 wells ELISA plates and read in an ELISA reader by Bradford method (1976). Aliquots (30 ug of protein) were treated with gel running buffer (Laemli SampleBuffer - BioRad ${ }^{\oplus}$ ) and $\beta$-mercaptoethanol at $95^{\circ} \mathrm{C}$ for $5 \mathrm{~min}$. Then, proteins were separated by vertical polyacrylamide gel electrophoresis SDS-PAGE $12 \%$. After electrophoresis, they were transferred to a nitrocellulose membrane in a wet transfer system. Blocking, washing and antibodies incubation procedures were performed in accordance with the manufacturer's instructions. Nonspecific protein binding was blocked with skim milk (MO$\mathrm{LICO}^{\circledR}$ ) at $3 \%$ in TBST buffer for $1 \mathrm{~h}$ at room temperature. Then, the membranes were incubated overnight with primary anti-aquaporin1 antibodies (1:1000 concentration; Millipore ${ }^{\circledR}$ Temecula, USA, AB2219) and anti-aquaporin-5 (1:500 concentration; Millipore ${ }^{\circledR}$ Temecula, USA, AB15858), which were diluted in TBST.

Subsequently, the membranes were washed in TBST and incubated in secondary antibodies (1:200 concentration; HRP SIGMA ${ }^{\circledR}$, USA), specific for each primary antibody, diluted in TBST for $2 \mathrm{~h}$ and then washed with TBST. The immunoreactive components were revealed by a luminescence kit (Amersham ECL ${ }^{\mathrm{TM}}$ Western Blotting Detection
Table 1

Animals weights and submandibular gland stereology and weights.

\begin{tabular}{lll}
\hline Parameters & Groups \\
\cline { 2 - 3 } & Control $(\mathrm{n}=6)$ & Irradiated $(\mathrm{n}=6)$ \\
\hline Animal weight (g) & $195.80 \pm 2.39$ & $196.70 \pm 4.77$ \\
Submandibular gland weight (mg) & $182.70 \pm 14.83$ & $159.40 \pm 3.63^{*}$ \\
Acini volume (\%) & $60.66 \pm 2.09$ & $59.14 \pm 1.77$ \\
Ductal volume (\%) & $23.94 \pm 2.42$ & $23.67 \pm 1.89$ \\
Stromal volume (\%) & $15.41 \pm 0.48$ & $17.19 \pm 1.24$ \\
\hline
\end{tabular}

Values are expressed as mean \pm SEM. $\mathrm{p}>0.05$. Test t Student.

$* \mathrm{p}=0.0078$.

Reagent Select) GE Healthcare ${ }^{\circledR}$ and the optical density of each band was measured by Image ${ }^{\circledast}{ }$ Windows ${ }^{\circledR}$ software, normalized for GAPDH density (1:800 concentration; G9545, SIGMA ${ }^{\circledR}$, USA). Data were expressed as mean \pm standard error of the mean. Comparisons between the animal groups were done by Student's t-test. Differences in p-values $<0.05$ were considered statistically significant.

\section{Results}

\subsection{Stereology and histomorphometry}

At the end of the experimental period, the weight of the animals showed no significant difference between the groups. However, there was significant decrease in the weight of submandibular glands in the animals of the irradiated group when compared with the control group (Table 1).

Stereological results showed that irradiation treatment (single dose; $7.5 \mathrm{~Gy}$ ) did not alter the volume percentage of the ducts, acini and stroma as compared to the control group (Table 1).

Data regarding the duct and lumen diameter average values, as well as the duct epithelium height also showed no significant differences. However, epithelium height/lumen ratio analysis showed a significant difference $(\mathrm{p}=0.0266)$, as shown in Table 2 .

\subsection{Immunohistochemistry}

The analysis of slides prepared for AQP1 immunolocalization of the control group animals showed the presence of this protein in the endothelium of vascular channels around the acini. AQP1 reactivity was also detected in blood cells within these vessels. Moreover, there is a clear cytoplasmic labelling for AQP1, with granules appearing in the ductal cells without specific labelling in the apical and basal membranes. Still, no immunolabeling was observed in the cytoplasm and acinar cell membranes (Fig. 1A).

Animals from the irradiated group maintained the same location pattern for the AQP1 in the glandular epithelium, with a decrease in the immunohistochemistry labelling intensity, especially in the endothelium, when compared with the control group (Fig. 1B).

In the control group animals, strong labelling for AQP5 was

Table 2

Mean and standard error mean ( \pm ) of ductal and luminal diameter values, ductal epithelial height e ratio between height and epithelium and duct/lumen.

\begin{tabular}{lll}
\hline Parameters $(\mu \mathrm{m})$ & Groups \\
\cline { 2 - 3 } & Control $(\mathrm{n}=6)$ & Irradiated(n=6) \\
\hline Duct & $48.71 \pm 1.82$ & $47.90 \pm 1.33$ \\
Lumen & $6.93 \pm 0.47$ & $7.90 \pm 0.48$ \\
Epithelial height & $45.63 \pm 1.62$ & $43.22 \pm 1.29$ \\
Ratio epithelium height/lumen & $6.68 \pm 0.35$ & $5.54 \pm 0.26^{*}$
\end{tabular}

Values are expressed as mean \pm SEM. $\mathrm{p}>0.05$ Test $\mathrm{t}$ Student. $* \mathrm{p}=0.0266$. 


\section{Control}
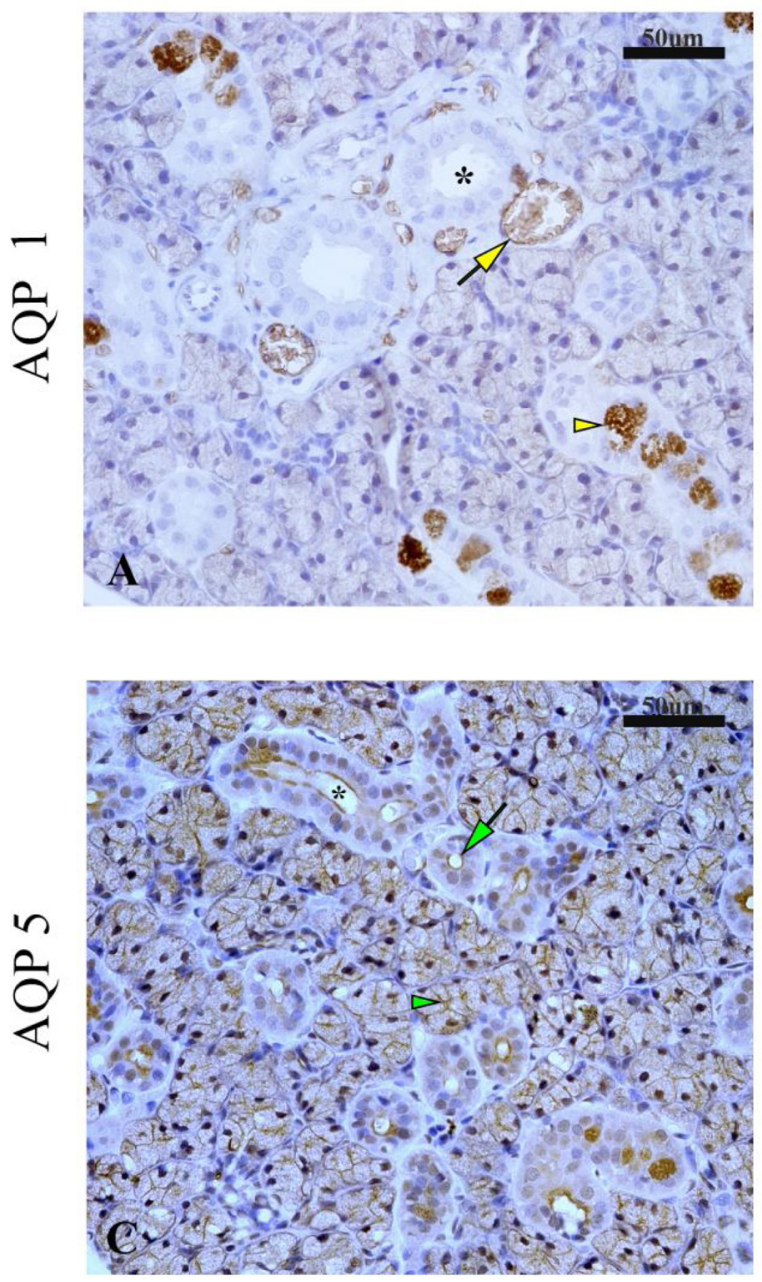

\section{Irradiated}
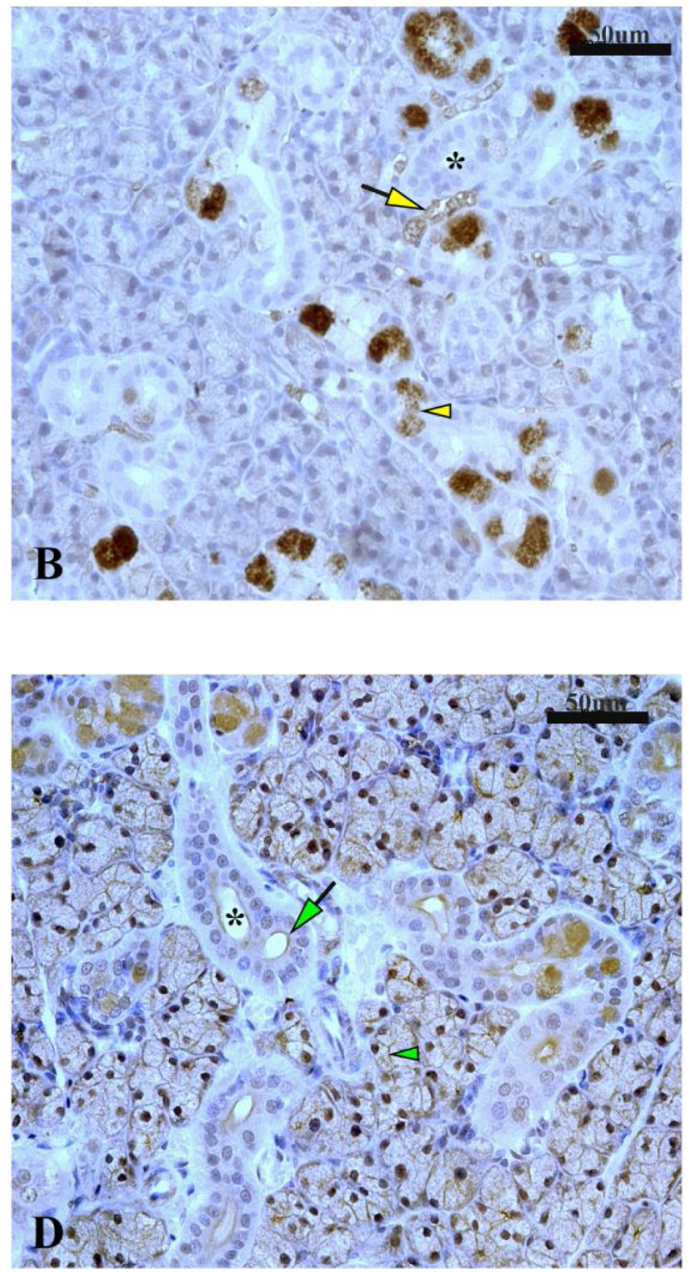

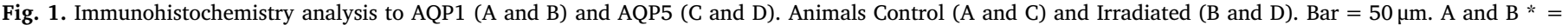
Ductal Lumen; $\rightarrow=$ vessel; $\boldsymbol{\sim}=$ granules; $\mathrm{C}$ and $\mathrm{D} *=$ ductal lumen; $\rightarrow=$ apical duct cells; $\boldsymbol{\nabla}=$ apical and basolateral membrane acinar cells.

observed in the apical and basolateral membranes of the acinar cells of the submandibular gland, and a more disperse labelling was observed in the cytoplasm of these cells. Also, weak labelling for AQP5 was observed in the apical region of the intercalated duct cells (Fig. 1C).

The immunohistochemistry analysis for the AQP5 in the submandibular gland of animals that underwent the irradiation protocol showed a distribution pattern for this AQP similar to the pattern observed in the control group with reduced labelling intensity (Fig. 1D).

\subsection{Western blotting}

Through western blotting, we confirmed a drop in the AQP1 protein levels in the submandibular gland of irradiated animals when compared to the animals of control group, as shown in immunohistochemistry analysis.

The negative results regarding AQP5 protein levels in the submandibular gland showed a change in the levels of this protein between the control and the treated groups. However, there was no significant statistical result (Fig.2). This result contrasts the evidence of a drop of AQP5 labelling, detected by immunohistochemistry (Fig. 1C, D). Despite a discrepancy in the results between immunohistochemistry and western blotting, we chose to respect the biological effect observed in immunohistochemistry, however, without disconsider the statistics used for protein level quantification by western blotting.

\section{Discussion}

Several studies have shown that radiation can cause glandular epithelial damage (Cherry and Glucksmann, 1959; Frank et al., 1965; Elzay et al., 1969; Savage et al., 1985; Ahlner et al., 1993; Friedrich et al., 2002; Nagler, 2003; Radfar and Sirois, 2003; Vier-Pelisser et al., 2005; Boraks et al., 2008), leading to salivary gland hypofunction and xerostomia. It seems plausible that functional loss occurs by structural changes imposed on these tissues by radiation and, therefore, alterations occur in the parenchyma and stroma of these glands. In general, studies describe the acinar atrophy as the most frequent histological finding (Cherry and Glucksmann,1959; Frank et al., 1965; Ahlner et al., 1993; Nagler, 2003; Radfar and Sirois, 2003; Vier-Pelisser et al., 2005), which is characterized by size reduction of acini or parenchymal tissue loss, accompanied by fibrosis or increase in interstitial connective tissue (Radfar and Sirois, 2003; Vier-Pelisser et al., 2005). Inflammatory stroma alterations were also reported, as well as cytoplasm vacuolation and apoptosis (Savage et al., 1985; Boraks et al., 2008).

Regarding the irradiation protocol, note that studies diverge in relation to the intensity and fractionation of the dose, so that while some experiments used a single dose (Ahlner et al., 1993; Nagler, 2003), others fractionated the radiation delivery (Cherry and Glucksmann,1959; Elzay et al., 1969; Radfar and Sirois, 2003; VierPelisser et al., 2005). Therefore, there seems to be a consensus that there is a relationship between the dose and the damage caused, so that 


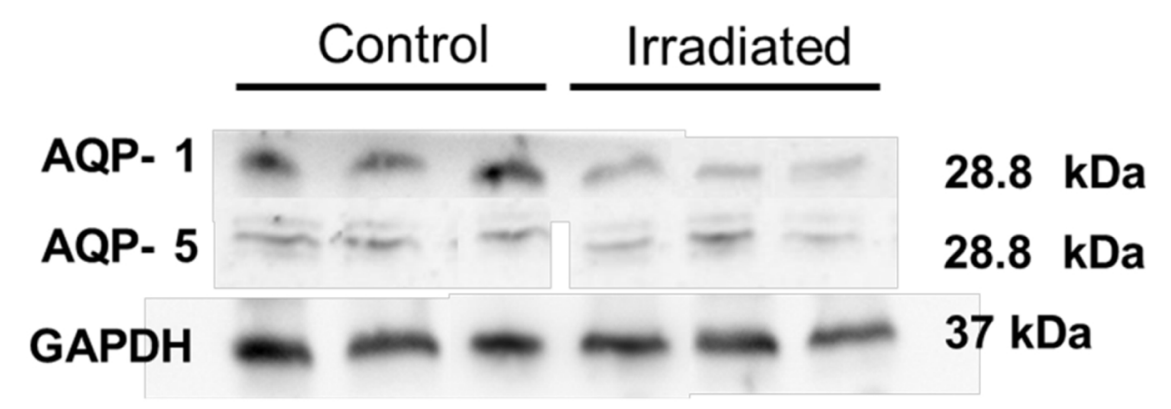

Experimental Groups

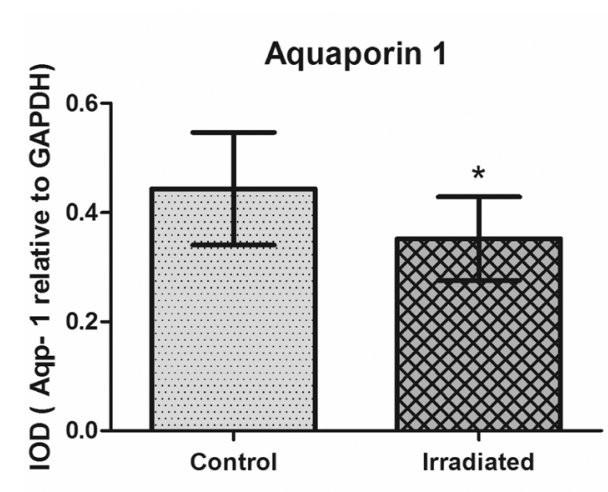

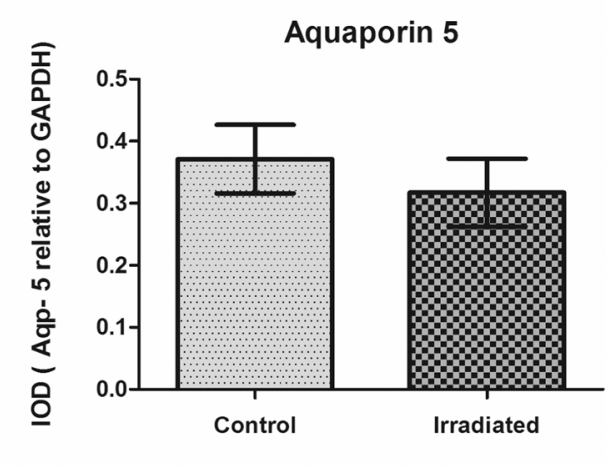

Experimental Groups
Fig. 2. AQP1 and AQP5 protein levels of submandibular gland samples by Western blot analysis. The graphs represent the relative expression of integrated optical density for AQP1 and AQP5 proteins, normalized by GAPDH and expressed as mean \pm SEM. The asterisk represents statistical difference of irradiated group compared to the control group $(\mathrm{p}<0.05)$. more intense transformations are observed in response to higher doses. Because of that, the present study proposed to investigate the functional impacts and identify possible morphological changes induced by low radiation in rat submandibular gland.

After analysis of the collected data for parenchymal and stroma volume evaluation, there was no significant difference between the groups, which contrasts the background literature. This contrast can be explained by taking into consideration that the radiation dose used in the experiment - a single dose of $7.5 \mathrm{~Gy}$ - is smaller than the dose used in selected experiments in the literature, ranging from 15 to $76.5 \mathrm{~Gy}$.

There were also no significant differences in the analysis of the average values of diameter and lumen and the height of epithelial wall and ductal epithelium. However, a significant difference $(p=0.0266)$ in the epithelium height/lumen ratio was observed, which suggests a narrowing of the duct wall. This difference seems to be explained by the fact that the epithelium height measurements showed a slight decrease in contrast to a slight increase of the lumen measurements, although not evident in isolation, when combined, it showed a significant difference. Thus, this result added to the evidence of decrease of gland weight, corroborating the thesis often found in background literature, that irradiation can lead to tissue atrophy. Lastly, another relevant finding is that irradiation did not alter the weight of the animals after treatment, showing an isolated effect on the submandibular gland.

The data in this study show the presence of AQP1 in erythrocytes and the endothelium of blood vessels surrounding ducts and acini of submandibular gland in the animals of both the control and irradiation groups. It seems clear and widely accepted in literature the AQP1 location pattern in erythrocytes (Li et al., 2006a, 2006b; Aure et al., 2014) and endothelial cells of vessels and capillaries that supply glandular tissues of rats and mice (Li et al., 2006a, 2006b; Delporte, 2013; Aure et al., 2014) and humans (Gresz et al., 2001; Delporte, 2013). Probably, AQP1 presence in these blood vessels is related to water removal from the tissue after reabsorption by epithelial cells.

In humans, as revised by Delporte (2013), APQ1 location is not restricted to endothelial cells, but is also associated to myoepithelial cells that surround submandibular and parotid gland acini. In this case, the presence of AQP1 in myoepithelial cells might be related to the contraction ability of these cells, resulting in acinar constriction to drive the primary salivary flow towards the mouth (Delporte and Steinfeld, 2006). Thus, for all studies to date, AQP1 was not localized in the epithelial cells of salivary glands, which suggests a secondary role of this protein in the synthesis of saliva under normal conditions (Gresz et al., 2001; Delporte and Steinfeld, 2006; Delporte, 2013; Aure et al., 2014).

However, in contrast to the literature, we have identified granules with intense and consistent labelling for AQP1 in the cytoplasm of ductal cells of a large part of the submandibular gland ducts. Our hypothesis to explain the presence of these granules is that they are probably intracellular vesicles for AQP1 storage for rapid protein turnover. Still, they would be positive AQP1 intracellular vesicles with ductal cell volume control since aquaporins are generally present in the intracellular organelles membrane, where they regulate cell and organelle volume (Nozaki et al., 2008).

In our study, the standard AQP1 location in the submandibular gland of animals of the irradiated group remained similar to the one observed in animals of the control group. However, a decrease in AQP1 protein levels of irradiated animals was detected when compared to the control group animals' levels. Different results were reported by Li et al. (2006) where the authors reported no difference in AQP reaction intensity in salivary glands of rats exposed to 15-Gy single radiation dose when compared to the control group. Conflicting reports on the AQP1 intensity could be explained by differences in the choice of experimental protocols used in each study.

Therefore, according to our data, the decrease in endothelial AQP1 may have indirectly delayed the water removal from the lumen towards the epithelium. Considering that the removal of water from the lumen into the epithelium, performed by another water channel, is absorbed by periductal vascular channels to be removed, a delay in water absorption caused by AQP1 activity decrease would explain the slight lumen increase observed in histomorphometry.

Thus, in an unprecedented manner, our results suggest that changes in AQP1 protein levels in irradiated salivary glands could be responsible for triggering morphological changes in this gland. Perhaps it is a progressive, dependent on the dose and time of exposure to radiation.

Our findings showed labelling for AQP5 in the apical membrane of ductal cells delimiting the lumen of intercalated duct and in the 
membrane of acinar cells, with discrete cytoplasmic labelling.

The presence of AQP5 in acinar and ductal cells was widely discussed in literature, although its location and role in the physiology of saliva synthesis involve controversial aspects. Generally, AQP5 is described as seen in the apical membrane of acinar cells of rodents (Funaki et al., 1998; Delporte and Steinfeld, 2006; Li et al., 2006a, 2006b; Takakura et al., 2007; Larsen et al., 2011; Matsuzaki et al., 2012; Delporte, 2013; Susa et al., 2013; Takahashi et al., 2015) and humans (Gresz et al., 2001; Delporte and Steinfeld, 2006; Delporte, 2013), while some authors also described it in the basolateral membrane and cytoplasm of these cells (Larsen et al., 2011; Matsuzaki et al., 2012; Susa et al., 2013). Regarding the ductal cells, many studies diverge when it comes to its occurrence (Cherry and Glucksmann,1959; Delporte and Steinfeld, 2006; Takakura et al., 2007; Larsen et al., 2011; Matsuzaki et al., 2012) or absence (Funaki et al., 1998; Li et al., 2006a, 2006b) in the intercalated duct.

Studies with knockout mice for AQP5 have shown that the absence of this AQP subtype leads to an approximately $60 \%$ reduction of saliva secretion and increase of its viscosity (Ma et al., 1999). Thus, a crucial role in saliva secretion for this AQP is suggested. Furthermore, the presence of AQP5 in intercalated ducts of the submandibular gland suggests that this protein may be involved in the absorption and/or secretion of small solutes, a fact that requires further investigation (Delporte and Steinfeld, 2006).

Matsuzaki et al. (2012) analyzed the presence of AQP5 in rat and mice parotid, sublingual and submandibular glands, with a particularity that this labelling was discrete and localized only in the apical membrane in rats and more evident and also localized in the basolateral membrane in mice. Regarding the ductal cells, the author described strong positive labelling for AQP5 in the apical membrane of intercalated duct cells in submandibular gland and negative for striated ducts and excretory ducts of both rat glands, while in mice the labelling was discrete in intercalated duct and negative in other ducts. The presence of AQP5 only in intercalated ducts in both mice and rat, and not in other ducts, can be explained by the physiology of saliva production. Thus, a primary saliva (produced by the acinar cells) into secondary saliva, takes place in the intercalated ducts through ionic exchange mediated by osmotic concentration gradient. Thus, $\mathrm{Na}+$ and $\mathrm{Cl}$ - are reabsorbed, while $\mathrm{K}+$ and $\mathrm{HCO} 3$ - are incorporated, converting an originally isotonic fluid into a hypotonic fluid. In this scenario, the need for intercalated duct permeability becomes evident, while the striated and excretory ducts show as potentially impermeable, since its function is limited to conducting fluid to the oral cavity, with no other changes in its composition.

Several experiments were performed to assess the effect of irradiation over AQPs, considering the radiosensitivity of these proteins and the isolated role of each AQP in the salivary gland hypofunction. It is well established in literature that irradiation alters salivary gland function, resulting in changes in saliva volume and composition pattern (Johnson et al., 1993; Vier-Pelisser et al., 2005; Jham and Freire, 2006; Takakura et al., 2007; Asari et al., 2009; Deasy et al., 2010; Lucena et al., 2010; Vieira et al., 2012; Liu et al., 2012; Wong, 2014; Saleh et al., 2015; Pinna et al., 2015; Takahashi et al., 2015), and therefore, AQPs may play a relevant role in this scenario. In the present study, submandibular glands showed AQP5 labelling drop after irradiation exposure.

Delporte and Steinfeld (2006) and Delporte (2013) reviewed the literature and established a relationship between salivary flow deficiency and AQP5 expression decrease in irradiated rats' intercalated duct and acinar cells. Li et al. (2006) assessed in their study the AQP5 reaction exposed to a single dose of $15 \mathrm{~Gy}$ radiation and found AQP5 labelling approximately $60 \%$ lower 3 days after irradiation protocol and $44 \%$ lower after 30 days when compared to a non-irradiated group. Thus, the authors concluded that the drop of AQP5 levels may play a role in the process of salivary flow reduction in irradiated salivary glands. Other experiments (Takakura et al., 2007; Asari et al., 2009) have also shown that AQP5 presents sharp decrease in activity after radiation. Takakura et al. (2007) showed an immunofluorescence drop of both AQP5 and AQP5 mRNA in acinar cells of mice exposed to $15 \mathrm{~Gy}$ $\mathrm{X}$ radiation. Asari et al. (2009), after analyzing rat parotid glandules, also reported a decrease in AQP5 expression after a single dose of $15 \mathrm{~Gy}$ irradiation.

\section{Conclusions}

In summary, we confirm AQP1 presence in the endothelium of large-calibre and small-calibre blood vessels and in blood cells within these vessels, as well as AQP5 presence in ductal cells delimiting the lumen of intercalated duct and within the cytoplasm and apical and basolateral membranes of acinar cells. Also, the radiosensitivity of these proteins seems clear, confirmed by the decrease of its labelling in irradiated animal glands, although the mechanism related to this process remains unclear.

Finally, it is known that in other tissues, AQPs can occupy the same membrane domain and dynamically act to maintain tissue homeostasis. Therefore, in our study, the animals that were submitted to irradiation did not show severe structural and morphological submandibular gland changes due to possible changes in the dynamics of these water channels in an attempt to preserve its regular physiology. In addition, based on our findings, it is possible to suggest that the presence of AQP1 is essential for the structural maintenance of the submandibular gland. Therefore, changes in AQP1 protein levels may trigger structural changes in the submandibular gland.

To finish, based on our results, it is also possible to conclude that irradiation, even in a low single dose, does not lead to severe morphological changes in the submandibular gland, but is sufficient to alter the function of the salivary gland.

\section{Author contributions}

M.V.T.A., T.M.S. and M.M.C performed the experiments; R.F.D., M.A.S, A.B.C. and G.V.A. designed the study; M.A.S. analyzed the morphological data; and M.V.T.A. and R.F.D. analyzed the data and wrote the manuscript, with contributions from all the authors.

\section{Funding}

This work was supported by a grant from the São Paulo Research Foundation (FAPESP) [2013/07203-4].

\section{Acknowledgement}

We thank Mr. Gelson Rodrigues for his technical support.

\section{References}

Ahlner, B.H., Hagelqvist, E., Lind, M.G., Rudén, B.I., 1993. Irradiation of rabbit submandibular glands. Histolgy and morfometry after 15 Gy. Acta Otolaryngol. 113, 210-219.

Asari, T., Maruyama, K., Kusama, H., 2009. Salivation triggered by pilocarpine involves aquaporin-5 in normal rats but not in irradiated rats. Clin. Exp. Pharmacol. Physiol. $36,531-538$.

Aure, M.H., Ruus, A.K., Galtung, H.K., 2014. Aquaporins in the adult mouse submandibular and sublingual salivary glands. J. Mol. Histol. 45, 69-80.

Boraks, G., Tampelini, F.S., Pereira, K.F., Chopard, R.P., 2008. Effect of ionizing radiation on rat parotid gland. Braz. Dent. J 19, 73-76.

Bradford, M.M., 1976. A rapid and sensitive method for the quantitation of microgram quantities of protein utilizing the principle of protein-dye binding. Anal. Biochem 72, $248-254$.

Cherry, C.P., Glucksmann, A., 1959. Injury and repair following irradiation of salivary glands in male rats. Br. J. Radiol. 32, 596-608.

Deasy, J.O., Moiseenko, V., Marks, L., Chao, K.S., Nam, J., Eisbruch, A., 2010.

Radiotherapy dose-volume effects on salyvary gland function. Int. J. Radiat. Oncol. Biol. Phys. 76, S58-S63.

Delporte, C., 2013. Aquaporins in salivary glands and pancreas. Biochim. Biophys. Acta $4165,351-356$. 
Delporte, C., Steinfeld, S., 2006. Distribution and roles of aquaporins in salivary glands. Biochim. Biophys. Acta 1758, 1061-1070.

Elzay, R.P., Levitt, S.H., Sweeney, W.T., 1969. Histologic effect of fractioned doses of selectively applied megavoltage irradiation on the major salivary glands of the albino rat. Radiology 93, 146-152.

Frank, R.M., Herdly, J., Philippe, E., 1965. Acquired dental defects and salivary gland lesions after irradiation for carcinoma. J. Am. Dent. Assoc. 70, 868-883.

Friedrich, R.E., Bartel-Friedrich, S., Holzhausen, H.J., Lautenschläger, C., 2002. The effect of external fractionated irradiation on the distribution pattern of extracellular matrix proteins in submandibular salivary glands of the rat. J. Craniomaxillofac. Surg. 30 246-254.

Funaki, H., Yamamoto, T., Koyama, Y., Kondo, D., Yaoita, E., Kawasaki, K., Kobayashi, H., Sawaguchi, S., Abe, H., Kihara, I., 1998. Localization and expression of AQP5 in cornea, serous salivary glands, and pulmonary epithelial cells. Am. J. Physiol. 275, 1151-1157.

Gresz, V., Kwon, T.H., Hurley, P.T., Varga, G., Zelles, T., Nielsen, S., Case, R.M., Steward, M.C., 2001. Identification and localization of aquaporin water channels in human salivary glands. Am. J. Physiol. Gastrointest. Liver Physiol. 281, G247-G254.

Jensen, S.B., Vissink, A., 2014. Salivary gland dysfunction and xerostomia in Sjögren's syndrome. Oral Maxillofac. Surg. Clin. N. Am. 26, 35-53.

Jham, B.C., Freire, A.R.S., 2006. Complicações bucais da radioterapia em cabeça e pescoço. Rev. Bras. Otorrinolaringol. 72, 704-708.

Johnson, J.T., Ferretti, G.A., Nethery, W.J., Valdez, I.H., Fox, P.C., Ng, D., Muscoplat, C.C., Gallagher, S.C.N., 1993. Oral pilocarpine for post-irradiation xerostomia in patients with head and neck cancer. Engl. J. Med. 329, 390-395.

Larsen, H.S., Aure, M.H., Peters, S.B., Larsen, M., Messelt, E.B., Kanli Galtung, H., 2011. Localization of AQP5 during development of the mouse submandibular salivary gland. J. Mol. Histol. 42, 71-81.

Li, J., Lee, S., Choi, S.-Y., Lee, S.J., Oh, S.-B., Lee, J.-H., Chung, S.C., Kim, J.-S., Lee, J.H., Park, K., 2006a. Effects of pilocarpine on the secretory acinar cells in human submandibular glands. Life Sci. 79, 2441-2447.

Li, Z., Zhao, D., Gong, B., Xu, Y., Sun, H., Yang, B., Zhao, X., 2006b. Decreased saliva secretion and down-regulation of AQP5 in submandibular gland in irradiated rats. Radiat. Res 165, 678-687.

Liu, B., Dion, M.R., Jurasic, M.M., Gibson, G., Jones, J.A., 2012. Xerostomia and salivary hypofunction in vulnerable elders: prevalence and etiology. Oral Surg. Oral Med. Oral Pathol. Oral Radiol. 114, 52-60.

Lucena, A.A.G., Costa, E.B., Alves, P.M., Figueiredo, R.L.Q., Pereira, J.V., Cavalcanti, A.L., 2010. Fluxo salivar em pacientes idosos. RGO - Rev Gaúcha Odontol 58, 301-305.

Ma, T., Song, Y., Gillespie, A., Carlson, E.J., Epstein, C.J., Verkman, A.S., 1999. Defective secretion of saliva in transgenic mice lacking aquaporin-5 water channels. J. Biol. Chem 274, 20071-20074.

Matsuzaki, T., Susa, T., Shimizu, K., Sawai, N., Suzuki, T., Aoki, T., Yokoo, S., Takata, K., 2012. Function of the membrane Water channel aquaporin-5 in the salivary gland. Acta Histochem. Cytochem. 45, 251-259.
Minicucci, E.M., Pires, R.B., Vieira, R.A., Miot, H.A., Sposto, M.R., 2013. Assessing the impact of menopause on salivary flow and xerostomia. Aust. Dent. J. 58, 230-234.

Nagler, R.M., 2003. Effects of head and neck radiotherapy on major salivary glands animal studies and human implications. In Vivo 17, 369-375.

Nikolopoulou, F., Tasopoulos, T., Jagger, R., 2013. The prevalence of xerostomia in patients with removable prostheses. Int. J. Prosthodont. 26, 525-526.

Nozaki, K., Ishii, D., Ishibashi, K., 2008. Intracellular aquaporins: clues for intracellular water transport? Pflug. Arch. 456, 701-707.

Pinna, R., Campus, G., Cumbo, E., Mura, I., Milia, E., 2015. Xerostomia induced by radiotherapy: an overview of the physiopathology, clinical evidence, and management of the oral damage. Ther. Clin. Risk Manag. 4, 171-188.

Radfar, L., Sirois, D.A., 2003. Structural and functional injury in minipig salivary gland following fractionated exposure to $70 \mathrm{~Gy}$ of ionizing radiation: an animal model for human radiation-induced salivary gland injury. Oral Surg. Oral Med. Oral Pathol. Oral Radiol. 96, 267-274.

Rosa, B.L., Zuccolotto, M.C.C., Bataglion, C., Coronatto, E.A.S., 2008. Odontogeriatria - a saúde bucal na terceira idade. RFO 13, 82-86.

Saleh, J., Figueiredo, M.A., Cherubini, K., Salum, F.G., 2015. Salivary hypofunction: an update on aetiology, diagnosis and therapeutics. Arch. Oral Biol. 60, 242-255.

Savage, N.W., Adkins, K.F., Kruger, B.J., 1985. The effects of fractionated megavoltage Xirradiation on the rat submandibular gland: an assessment by light microscopy and autoradiography. Aust. Dent. J. 30, 1-7.

Susa, T., Sawai, N., Aoki, T., Iizuka-Kogo, A., Kogo, H., Negishi, A., Yokoo, S., Takata, K., Matsuzaki, T., 2013. Effects of repeated administration of pilocarpine and isoproterenol on aquaporin-5 expression in rat salivary glands. Acta Histochem. Cytochem. 46, 187-197.

Takahashi, A., Inoue, H., Mishima, K., Ide, F., Nakayama, R., Hasaka, A., Ryo, K., Ito, Y., Sakurai, T., Hasegawa, Y., Saito, I., 2015. Evaluation of the effects of quercetin on damaged salivary secretion. PLoS One 10, e0116008.

Takakura, K., Takaki, S., Takeda, I., Hanaue, N., Kizu, Y., Tonogi, M., Yamane, G.Y., 2007. Effect of cevimeline on radiation-induced salivary gland dysfunction and AQP5 in submandibular gland in mice. Bull. Tokyo Dent. Coll. 48, 47-56.

Verkman, A.S.J., 2005. More than just water channels: unexpected celullar roles of aquaporins. Cell Sci. 118, 3225-3232.

Verkman, A.S., 2009. Aquaporins: translating bench research to human disease. J. Exp. Biol. 212, 1707-1715.

Verkman, A.S., Mitra, A.K., 2000. Structure and function of aquaporin water channels. Am. J. Physiol. Renal Physiol 278, F13-F28.

Vieira, D.L., Leite, A.F., Melo, N.S., Figueiredo, P.T.S., 2012. Tratamento odontológico em pacientes oncológicos. Oral Sci. 4, 37-42.

Vier-Pelisser, F.V., Amenábar, J.M., Cherubini, K., de Figueiredo, M.A.Z., Yurgel, L.S., 2005. Microscopic analysis of the effect of fractionated radiation therapy on submandibular gland of rat. Radiol. Bras. 38, 409-414.

Wong, H.M., 2014. Oral complications and management strategies for patients undergoing cancer therapy. ScientificWorldJournal 2014, 1-14. 